\title{
Effect of Silica and Tin Oxide Nanoparticles on Properties of Nanofibrous Electrospun Separators
}

\author{
M. Zaccaria, ${ }^{\text {a,z }}$ D. Fabiani, ${ }^{\text {a }}$ G. Cannucciari, ${ }^{a}$ C. Gualandi, ${ }^{\text {b }}$ M. L. Focarete, ${ }^{\text {b }}$ C. Arbizzani, ${ }^{\text {b,* }}$ \\ F. De Giorgio, ${ }^{b}$ and M. Mastragostino ${ }^{b}$
}

${ }^{a}$ Electric, Electronic and Information Engineering Department, Alma Mater Studiorum - Università di Bologna, Bologna, Italy

b “Giacomo Ciamician” Chemistry Department, Alma Mater Studiorum - Università di Bologna, Bologna, Italy

\begin{abstract}
Innovative separators able to improve the performance and safety of $\mathrm{Li}$-ion batteries are under investigation to meet the growing demand for large-size and high energy density electrochemical cells. In this work, highly porous nanofibrous Poly (vinylidene fluoride) (PVdF) separators loaded with oxide nanoparticles were produced by electrospinning. Silicon oxide and tin oxide nanoparticles were added to PVdF and membranes were characterized by SEM-EDS and TGA. The effect of nanoparticle addition on electrolyte uptake, mechanical properties and conductivity was investigated and such properties were compared to those of a commercial separator (Celgard 2400). Results showed that a small amount of additive can significantly improve the properties of PVdF electrospun membranes and that the different nanoparticles investigated in this work have different effect on membrane performances. In particular, the addition of $\mathrm{SiO}_{2}$ increases the rate of electrolyte uptake and the toughness of the electrospun membrane, while the addition of $\mathrm{SnO}_{2}$ decreases the rate of electrolyte uptake and increases the stiffness of the electrospun membrane. When loaded with nanoparticles, $\mathrm{PVdF}$ membranes maintain their insulating character also at high temperature. Preliminary electrochemical results on half-cell vs $\mathrm{Li}$ with $\mathrm{LiFePO}_{4}$ and electrospun separators showed good cycling performance, highlighting interesting features of this technology.

(C) The Author(s) 2015. Published by ECS. This is an open access article distributed under the terms of the Creative Commons Attribution Non-Commercial No Derivatives 4.0 License (CC BY-NC-ND, http://creativecommons.org/licenses/by-nc-nd/4.0/), which permits non-commercial reuse, distribution, and reproduction in any medium, provided the original work is not changed in any way and is properly cited. For permission for commercial reuse, please email: oa@electrochem.org. [DOI: 10.1149/2.0421506jes] All rights reserved.
\end{abstract}

Manuscript submitted November 14, 2014; revised manuscript received February 20, 2015. Published March 5, 2015. This was Paper 691 presented at the Como, Italy, Meeting of the IMLB, June 10-14, 2014.

Nowadays, lithium-ion batteries control electronic device market (e.g. laptops, mobile phones, cameras) due to their high energy density, high efficiency and long cycle life. However, a breakthrough is needed in order to fulfil new requirements of hybrid and electric vehicles and energy storage devices, in terms of costs, better electrochemical performances and safety. ${ }^{1-6}$

One of the most important component in the battery is the separator, which prevents physical and electric contact between electrodes while enabling electrolyte ions to flow there through. Its main requirements are: high open porosity and high electrolyte uptake, dimensional and chemical stability, low thickness and good mechanical properties to withstand battery assembly operations. ${ }^{7-9}$ Commercial microporous polyolefin separators fulfill some of these requirements, but still display low porosity, poor wettability and can undergo shrinking or melting in case of battery overheating, thus contributing to high internal resistance of the cell and limited cycle life..$^{10,11}$

Poly(vinylidene fluoride) (PVdF) and its co-polymers are considered valuable substitutes of polyolefins due to their good chemical resistance, high mechanical strength and excellent thermal stability. ${ }^{12,13}$ Recently, highly porous membranes produced by electrospinning has been widely investigated as separators in lithium-ion batteries due to the unique properties of the nanofibrous non-woven constructs: high porosity (typically 80-90\%), high pore interconnectivity and high surface area to volume ratio that lead to a large electrolyte uptake and excellent ion transport. ${ }^{14-18}$ This peculiar behavior makes electrospun mats suitable for high ionic conductivity and power intensive applications in lithium cells. However, the poor mechanical properties of electrospun non-wovens can limit their use for industrial applications, where high stresses and bending are applied during battery assembly. ${ }^{19}$ Improvements in membrane mechanical properties have been achieved either throughout thermal annealing of the membrane $e^{20,21}$ or by the addition of nanoparticles (e.g. metal oxide). ${ }^{22-25}$ It was also found that the addition of metal oxide nanoparticles, besides improving membrane mechanical properties, can increase electrolyte uptake, dimensional stability at high temperature, ionic conductivity and electrochemical stability. ${ }^{22,26-31}$

In this work, PVdF solutions containing different amounts of either fumed silica or tin oxide nanoparticles were electrospun to produce lithium-ion battery nanostructured separators. Properties of electrospun membranes loaded with nanoparticles have been evaluated in comparison to those of pristine PVdF electrospun membranes and of commercial Celgard separators to assess the effectiveness of nanoparticle loading on separator performance improvement.

\section{Materials and Methods}

Materials. - PVdF (Solef 6008) was kindly provided by Solvay Specialty Polymers (Bollate, Italy). Acetone (Ac), Dimethyl Sulfoxide (DMSO), Fumed Silica nanoparticles $\left(\mathrm{SiO}_{2}\right.$, average diameter: $\left.7 \mathrm{~nm}\right)$ and Tin oxide nanoparticles $\left(\mathrm{SnO}_{2}\right.$, average diameter $\left.<100 \mathrm{~nm}\right)$ were purchased from Sigma-Aldrich and used as received. Commercial Celgard 2400 separator (thickness: $25 \mu \mathrm{m}$, porosity: $37 \%$ ) was used for a comparative study.

For electrolyte uptake and contact angle experiments a solution of $1 \mathrm{M} \mathrm{CF}_{3} \mathrm{SO}_{3} \mathrm{Li}$ in Ethylene Carbonate (EC): Dimethyl Carbonate (DMC) $(1: 1 \mathrm{w} / \mathrm{w})$ was used (reagents supplied by Sigma-Aldrich) while a solution of $1 \mathrm{M} \mathrm{LiPF}_{6}$ in EC: DMC (1:1 w/w) (LP30, Merck) was used for conductivity measurements and electrochemical tests.

Separator fabrication. - $\mathrm{PVdF}$ was dissolved at a concentration of $15 \% \mathrm{w} / \mathrm{v}$ in Ac:DMSO (70:30, v/v). After polymer dissolution, nanoparticles were added to polymeric solutions in proper amounts in order to produce membranes containing either $1 \mathrm{wt} \%$ and $5 \mathrm{wt} \%$ of $\mathrm{SiO}_{2}$ or $0.5 \mathrm{wt} \%, 1 \mathrm{wt} \%$ and $5 \mathrm{wt} \%$ of $\mathrm{SnO}_{2}$. After 30 min of mechanical stirring homogeneous suspensions were achieved by sonicating the colloidal solutions for 10 minutes by using a UP200St "Hielscher" (Ultrasound Technology) working at $20 \mathrm{~W}$. The sonication was performed in an ice bath to limit solvent evaporation.

For the fabrication of PVdF separators a laboratory electrospinning machine was used (Spinbow Lab Unit, Spinbow S.r.l., Italy). The machine was equipped with a multi-jet linear sliding apparatus, equipped with 4 needles, a rotating collector and a syringe 
pumping system with adjustable flow rate. Solutions were electrospun by using the following operating conditions: voltage $=$ $16.5 \mathrm{kV}$, needle-to-collector distance $=15 \mathrm{~cm}$, flow rate per needle $=0.01 \mathrm{~mL} / \mathrm{min}$. The electrospinning process was carried out at room temperature and relative humidity $40-50 \%$. Membranes $20 \times 30 \mathrm{~cm}^{2}$ were produced for each type of solution composition and used for further characterization.

Material characterization.- Membrane morphology characterization and energy dissipation spectroscopy (EDS) were carried out by means of a scanning electron microscope (SEM) equipped with Fibermetric software (PHENOM PROX Desktop SEM) by applying an accelerating voltage of $15 \mathrm{kV}$ on samples sputter-coated with gold, in order to evaluate fiber quality, fiber diameter distribution and to analyze the presence of inorganic nanoparticles. Fiber diameter distribution was evaluated through the measurement of about 200 fibers by using the Fibermetric software (Phenom) and the results were given as average diameter \pm standard deviation.

Thermogravimetric analysis (TGA) were performed to evaluate thermal stability and to quantify the inorganic fraction in the separator, using a thermo-gravimetric analyzer (TA Instruments TGA2950) from RT to $600^{\circ} \mathrm{C}$ in air with a heating rate of $10^{\circ} \mathrm{C} / \mathrm{min}$.

Tensile tests were carried out with a tensile testing machine (Instron 4465 ) on rectangular electrospun membranes ( $5 \mathrm{~mm}$ wide). The gauge length was $20 \mathrm{~mm}$ and the cross-head speed was $2 \mathrm{~mm} / \mathrm{min}$. Tests were performed on 10 specimens for each mat and results were processed through the Weibull probability distribution, providing the $63.2^{\text {th }}$ percentiles ( $\alpha$, scale parameter) with the relevant confidence intervals at $90 \%$ probability. The following mechanical data were provided: (i) elastic modulus, (ii) stress-at-break and (iii) elongation-at-break.

Electrolyte uptake was evaluated through capillarity measurements. Each membrane $\left(1 \times 5 \mathrm{~cm}^{2}\right)$ was fixed to a rectangular PTFE frame and was vertically immersed in the electrolyte solution for a couple of millimeters. The electrolyte solution instantaneously wet the membrane and its level rose under the capillary action. Electrolyte uptake of the different membranes was evaluated by comparing the time needed for the electrolyte to reach the height of $4 \mathrm{~cm}$. The height of $4 \mathrm{~cm}$ was chosen to ensure the achievement of steady state condition in the rate of electrolyte uptake.

Static contact angle measurements were performed on electrospun membranes by using a KSV CAM101 instrument under ambient conditions by recording the side profiles of electrolyte drops for image analysis. The shape of the drop was recorded in a time range of $0-2 \mathrm{~s}$, by collecting an image every $66 \mathrm{~ms}$. At least four drops for each sample were tested.

Electronic conductivity of the membranes non-soaked in the electrolyte was measured. Samples placed between two electrodes have been subjected to DC $5 \mathrm{kV} / \mathrm{mm}$ electrical field. The charging current flowing through the separators was measured until the steady-state conduction current was reached. The high voltage electrode had a $27 \mathrm{~mm}$ diameter while the lower electrode was divided in a central electrode of around $15 \mathrm{~mm}$ diameter surrounded by a $27 \mathrm{~mm}$ guard ring connected to ground. This configuration was chosen to prevent a possible contribution of surface currents to the measurement. Each sample was preliminarily sputter-coated with gold replicating electrode area on sample. A sketch of the experimental apparatus is reported in Figure 1a, while the gold sputtering of electrospun and Celgard 2400 separators are shown in Figures $1 \mathrm{~b}$ and 1c, respectively. Thanks to this technique, the electronic conductivity can be determined by measuring the conduction current through an ammeter, as reported in the equations 1-4:

$$
J=\frac{I}{S}
$$

$$
J=\sigma \cdot E
$$

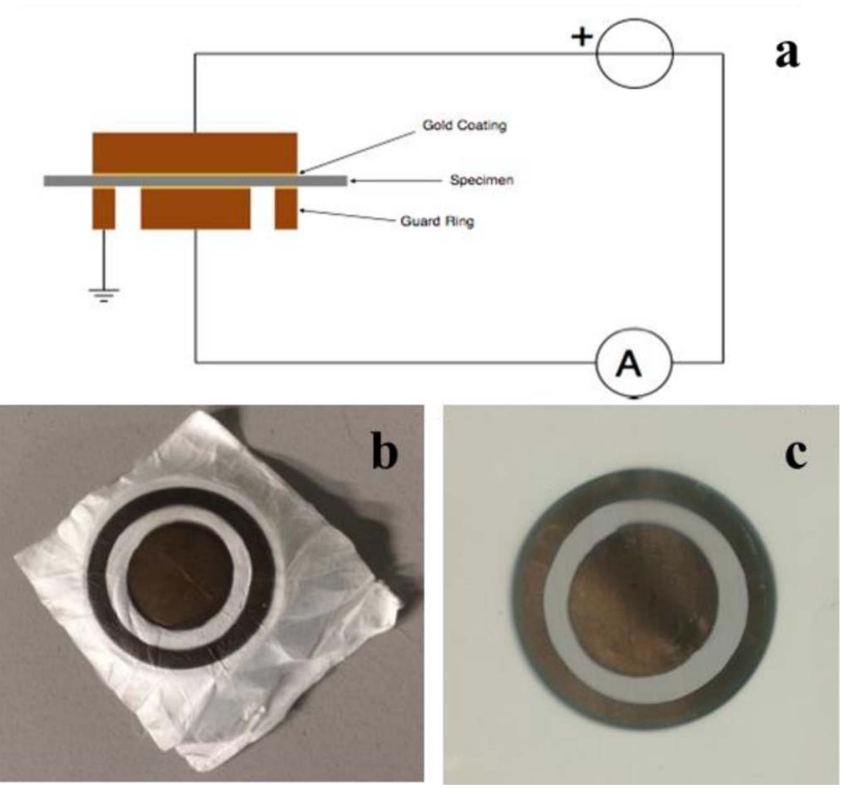

Figure 1. DC conductivity measurement system (a) and pictures of goldsputtered electrospun (b) and Celgard 2400 (c) separators.

$$
\begin{gathered}
E=\frac{V}{d} \\
\sigma=\frac{(E \cdot S)}{I}
\end{gathered}
$$

where $J=$ electric current density, $I=$ electric current, $S=$ electrode area, $\sigma=$ electronic conductivity, $E=$ electric field, $V=$ applied voltage, $d=$ sample thickness.

Pristine electrospun $\mathrm{PVdF}$ resistance was measured at $30^{\circ} \mathrm{C}$ by means of a conductivity meter (MeterLab CDM210 - Radiometer analytical). The membrane was soaked in LP30 electrolyte and interposed between two stainless steel blocking electrodes, in a Swagelok-like cell. MacMullin number was calculated as ratio between the resistivity of the separator soaked in electrolyte and the resistivity of the electrolyte $\left(7,53 \cdot 10^{3} \mathrm{Ohm} \cdot \mathrm{cm}\right)$.

Cell assembly.- Pristine PVdF and PVdF loaded with $0.5 \mathrm{wt} \%$ $\mathrm{SnO}_{2}$ were used in half cells vs. Li. Cell assembly was performed in a MBraun Labmaster SP glove box (water and oxygen content $<0.1$ ppm). The membrane thickness (about 40-50 $\mu \mathrm{m}$ ) was measured by a digital micrometer (Borletti MDE1, resolution $0.001 \mathrm{~mm}$ ) that applies a compressive force between 8 and $10 \mathrm{~N}$. The nanofibrous membrane soaked with $500 \mu \mathrm{L}$ of $\mathrm{LP} 30$ electrolyte, was put on $\mathrm{LiFePO}_{4}$ electrode and both placed in a "Swagelok-like" electrochemical cells vs. $\mathrm{Li}$ in excess and $\mathrm{Li}$ reference electrode. $\mathrm{LiFePO}_{4}$ electrode composition (in wt $\%$ ) was $90 \% \mathrm{LiFePO}_{4}$ (Advanced Lithium Electrochemistry Co.), $5 \%$ Super P (Erachem) conductive carbon and 5\% PVdF Kynar HSV 900 (Arkema). The electrodes had a $\mathrm{LiFePO}_{4}$ loading in the range of $5-7 \mathrm{mg} \mathrm{cm}^{-2}$. The electrochemical tests were carried out by a Biologic VMP multichannel potentiostat/galvanostat at $30^{\circ} \mathrm{C}$.

\section{Results and Discussion}

Electrospinning of PVdF dissolved in Ac:DMSO (70:30 v/v) at a concentration of $15 \% \mathrm{w} / \mathrm{v}$ led to sub-micrometric bead-free fibers with smooth fiber surface (Figure 2a). The process was carried out to produce $40-50 \mu \mathrm{m}$ thick membranes. It is worth noting that thickness of electrospun separators is significantly higher than that of commercial separators (i.e. $25 \mu \mathrm{m}$ ), due to the different nature of the two materials. Indeed, conventional separator is a laminate, which can be 

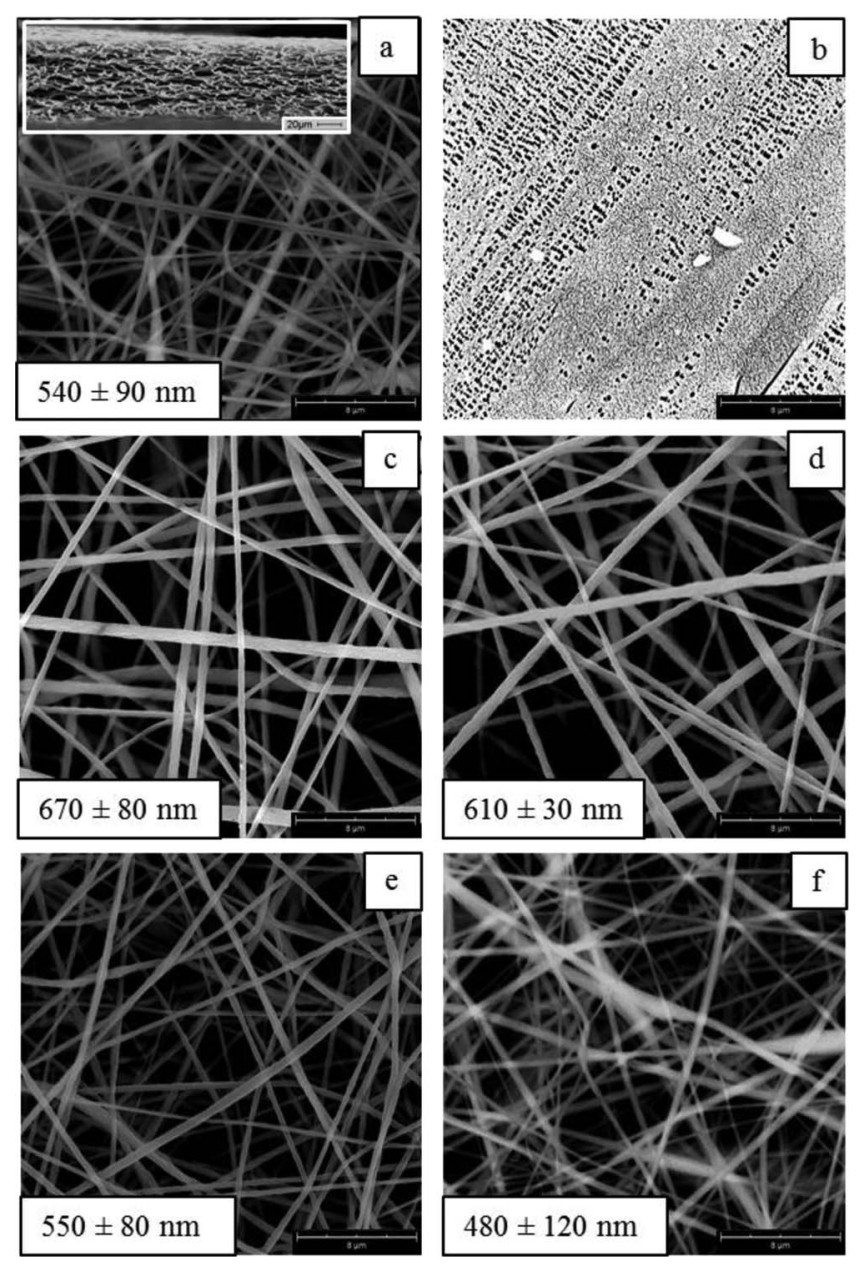

Figure 2. SEM images of PVdF pristine polymer (a transversal section is shown in the inset) (a), Celgard 2400 (b), and PVdF containing $1 \mathrm{wt} \% \mathrm{SiO}_{2}$ (c), $5 \mathrm{wt} \% \mathrm{SiO}_{2}$ (d), $1 \mathrm{wt} \% \mathrm{SnO}_{2}$ (e), $5 \mathrm{wt} \% \mathrm{SnO}_{2}$ (f); Scale bar $=8 \mu \mathrm{m}$.

realized in thin film, while electrospun membrane is not a film but a non-woven tissue made of several fibrous layers and requires higher thickness to avoid short-circuit. Experimental campaign on electrospun separators, not reported here for the sake of brevity, was carried out with the aim to optimize the thickness needed to prevent short circuits, i.e. $40-50 \mu \mathrm{m}$. However, the higher porosity and pore interconnectivity of electrospun membranes compared to Celgard (Figure $2 b)$ are expected to increase ionic conductivity and consequently decrease internal resistance of the cell, thus to better perform at high currents and in power-intensive applications. Indeed, MacMullin number measured on pristine electrospun PVdF was about 3, while that of Celgard 2400 is reported to be about $16 .^{32}$ An example of a transversal section of PVdF non-woven membrane is reported in the inset of Figure 2a. As can be seen, the path from the surface to the bottom of the membrane is characterized by a significant tortuosity, due to the randomly oriented pattern of fibers. Interconnected pores, even if large, do not cross directly the material, thus preventing short circuit if the membrane thickness is optimized.

Battery nanofibrous separators containing $1 \% \mathrm{w} / \mathrm{w}$ and $5 \% \mathrm{w} / \mathrm{w}$ of either $\mathrm{SiO}_{2}$ or $\mathrm{SnO}_{2}$ were successfully electrospun. Indeed, SEM images in Figure 2c-2f show that each electrospun membrane was made up of good quality fibers without bead-like defects. The distributions of fiber diameters (average values and standard deviations) are also reported (mean fiber diameters range between $480 \mathrm{~nm}$ and $670 \mathrm{~nm}$ ).

EDS spectra of electrospun membranes were collected to verify the presence of nanoadditives in electrospun mats. EDS spectra are reported in Figure 3 in the range $0-8 \mathrm{keV}$ since at energies higher than $8 \mathrm{keV}$ no peaks were detected. Samples filled with the nanoparticles
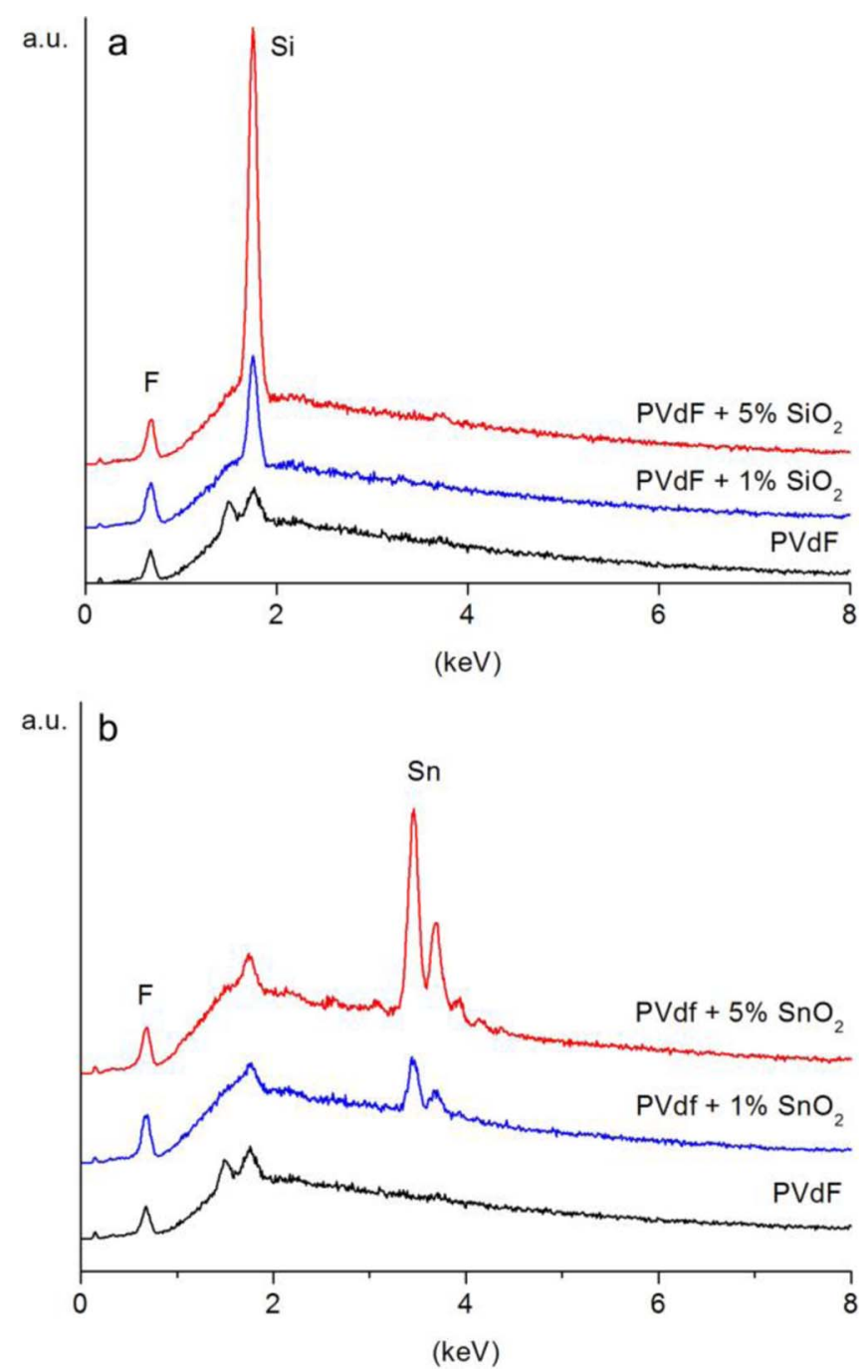

Figure 3. EDS spectra of $\mathrm{PVdF}$ samples loaded with $\mathrm{SiO}_{2}$ (a) and $\mathrm{PVdF}$ samples loaded with $\mathrm{SnO}_{2}$ (b).

showed the characteristic peaks of Si and Sn elements, whose intensities were proportional to the weight content of inorganic particle.

Thermal stability of separators was evaluated through TGA measurements (Figure 4). Nanoparticle addition did not change the thermal degradation mechanism of the polymer, neither the initial degradation temperature, that is about $320^{\circ} \mathrm{C}$ for all tested membranes. Pristine polymer reached zero mass at the end of the test. Samples containing

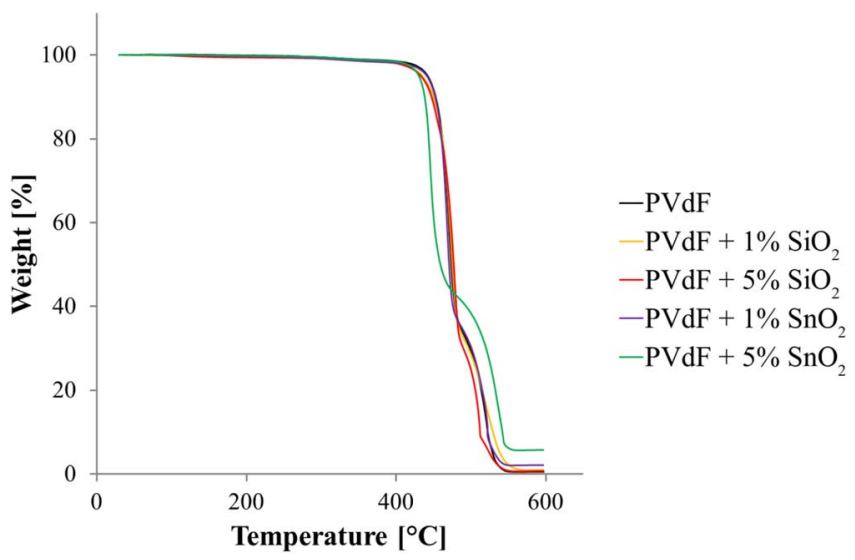

Figure 4. Thermogravimetric curves of PVdF electrospun samples. 


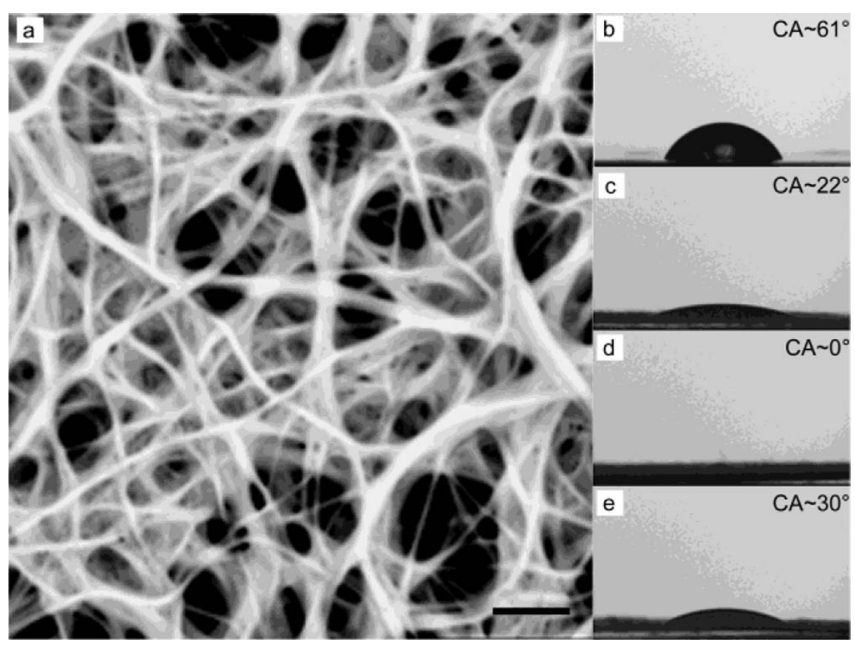

Figure 5. (a) SEM image of PVdF electrospun separator soaked in electrolyte; scale bar $=5 \mu \mathrm{m}$. Electrolyte drop in contact with Celgard (b), pristine PVdF (c) and $\mathrm{PVdF}$ containing $5 \mathrm{wt} \% \mathrm{SiO}_{2}$ (d) and $5 \mathrm{wt} \% \mathrm{SnO}_{2}$ (e).

$1 \mathrm{wt} \%$ and $5 \mathrm{wt} \%$ of $\mathrm{SnO}_{2}$ showed about $2 \%$ and $6 \%$ residue of the initial mass, respectively. Both samples containing silica showed a residue of only $1 \%$. This low value can be explained by hypothesizing that during the degradation of the sample, some volatile silicon-based compounds were generated. In particular, it is expected that the presence of hydrogen and fluorine in polymer chain led to the formation of gases at the high temperatures here considered, i.e silane $\left(\mathrm{SiH}_{4}\right)$ and tetrafluorosilane $\left(\mathrm{SiF}_{4}\right) .{ }^{25}$ However, the aforementioned EDS results confirmed qualitatively the presence of $\mathrm{SiO}_{2}$ in the fibers according to the expected amount.

Pristine PVdF fibers soaked in electrolyte and dried for SEM analysis (Figure 5a) displayed an increase in fiber diameter of almost twice its initial value (compare Figure 5a with Figure 2a), as a consequence of fiber swelling in electrolyte solution. Results of capillarity measurements for the electrospun separators are reported in Table I. The reported values were calculated by considering the time taken for the electrolyte to reach the height of $4 \mathrm{~cm}$ in the pristine $\mathrm{PVdF}$ as a reference (about $400 \mathrm{~s}$ ). Analyzing the data reported in Table I, it is possible to observe that the presence of nanoparticles inside the nanofibers significantly affects electrolyte uptake. In particular, $\mathrm{SiO}_{2}$ nanoparticles accelerate electrolyte uptake, while $\mathrm{SnO}_{2}$ nanoparticles slow down the process with respect to pristine polymer. This behavior could be associated to the high polar nature of $\mathrm{SiO}_{2}$ nanoparticles, which can locally increase membrane polarity, thus favoring electrolyte uptake. However, all the tested electrospun separators are able to uptake a higher amount of electrolyte than commercial Celgard 2400. Indeed, when the latter was immersed in electrolyte solution for capillary uptake measurements, the level of electrolyte after one hour rose a little bit and never reached the height of $4 \mathrm{~cm}$.

Contact angle measurements were also carried out to evaluate the wettability of the different separators by the electrolyte solution. Electrolyte drop on Celgard (Fig. 5b) displayed a contact angle of about $61^{\circ}$ and it was not completely absorbed by the separator. On the

Table I. Relative time to reach $\mathbf{4} \mathrm{cm}$ in capillarity measurements for electrospun samples, referred to pristine $\mathrm{PVdF}$ as reference.

Sample

Relative time to reach

$\mathrm{PVdF}$

$\mathrm{PVdF}+1 \% \mathrm{SiO}_{2}$

$\mathrm{PVdF}+5 \% \mathrm{SiO}_{2}$

$\mathrm{PVdF}+1 \% \mathrm{SnO}_{2}$

$\mathrm{PVdF}+5 \% \mathrm{SnO}_{2}$
Table II. Electronic conductivity of electrospun and Celgard 2400 separators at $25^{\circ} \mathrm{C}, 40^{\circ} \mathrm{C}$ and $70^{\circ} \mathrm{C}$.

\begin{tabular}{cccc} 
Sample & $\begin{array}{c}\text { Conductivity } \\
{[\mathrm{S} / \mathrm{m}] \text { at } 25^{\circ} \mathrm{C}}\end{array}$ & $\begin{array}{c}\text { Conductivity } \\
{[\mathrm{S} / \mathrm{m}] \text { at } 40^{\circ} \mathrm{C}}\end{array}$ & $\begin{array}{c}\text { Conductivity } \\
{[\mathrm{S} / \mathrm{m}] \text { at } 70^{\circ} \mathrm{C}}\end{array}$ \\
\hline $\mathrm{PVdF}$ & $1.8 \cdot 10^{-14}$ & $1.7 \cdot 10^{-13}$ & $7.2 \cdot 10^{-12}$ \\
$\mathrm{PVdF}+1 \% \mathrm{SiO}_{2}$ & $7.9 \cdot 10^{-14}$ & $2.9 \cdot 10^{-13}$ & $3.9 \cdot 10^{-12}$ \\
$\mathrm{PVdF}+5 \% \mathrm{SiO}_{2}$ & $1.3 \cdot 10^{-13}$ & n.d. & n.d. \\
$\mathrm{PVdF}+1 \% \mathrm{SnO}_{2}$ & $8.4 \cdot 10^{-14}$ & $5.0 \cdot 10^{-13}$ & $6.5 \cdot 10^{-12}$ \\
$\mathrm{PVdF}+5 \% \mathrm{SnO}_{2}$ & $7.9 \cdot 10^{-13}$ & n.d. & n.d. \\
Celgard 2400 & $1.4 \cdot 10^{-15}$ & $1.7 \cdot 10^{-15}$ & $4.5 \cdot 10^{-15}$
\end{tabular}

contrary, all mats were able to completely absorb the electrolyte drop within $2 \mathrm{~s}$ after the beginning of the analysis. However, by comparing the very initial stage of the experiments, differences in the rate of drop absorption emerged. In Figure $5 c-5 e$ the shape of the drops and the corresponding contact angles values at $66 \mathrm{~ms}$ are reported for pristine $\mathrm{PVdF}$ and for PVdF mats loaded with $5 \mathrm{wt} \%$ of nanoparticles. The presence of $\mathrm{SiO}_{2}$ accelerated electrolyte drop absorption so that at $66 \mathrm{~ms}$ the drop was already completely absorbed by the mat. On the contrary, the electrolyte contact angle at $66 \mathrm{~ms}$ in the case of $\mathrm{SnO}_{2}$ loading was higher when compared with the pristine PVdF mat, thus confirming the results of capillary measurements. It is pointed out that when only $1 \mathrm{wt} \%$ of nanoparticles were added to the polymer, no significant differences in contact angles were observed.

Electronic conductivity results are reported in Table II. At room temperature the values of conductivity of all electrospun mats are in the range of insulating materials. Indeed, electronic conductivity is well below $10^{-8} \mathrm{~S} / \mathrm{m}$, which is the limit value for a material to be considered insulating for electronic charge carriers. In order to investigate the change of electrical conductivity as a function of the temperature, the same analysis was carried out also at $40^{\circ} \mathrm{C}$ and $70^{\circ} \mathrm{C}$. These measurements were performed only on the nanostructured separators filled with $1 \mathrm{wt} \%$ of inorganic additives since we demonstrated that such a low concentration is enough to positively affect electrolyte uptake. At the high temperatures investigated, the electrospun membranes are still insulating materials, being the electronic conductivity much lower than $10^{-8} \mathrm{~S} / \mathrm{m}$. The Arrhenius plot of conductivity reported in Figure 6 shows that the addition of nanoparticles to PVdF has the effect of decreasing the activation energy related to electronic conduction mechanism. Therefore, the increase of electronic conductivity at high temperature is smaller in the case of loaded membranes with respect to pristine polymer. In addition, by considering the value of activation energy, at very high temperatures, close to thermal runaway, the loaded membranes have lower electronic conductivity than pristine $\mathrm{PVdF}$, thus ensuring higher safety against short circuit.

Figure 7 shows elastic modulus, stress-at-break and elongation-atbreak of PVdF separators. PVdF loaded with both type of additives in each weight concentration showed higher Young's moduli with respect to pristine PVdF (Figure 7a). Furthermore, the addition of $1 \mathrm{wt} \%$ of $\mathrm{SiO}_{2}$ led to a remarkable increase of elongation-at-break and a small increase of stress-at-break, thus making the membrane

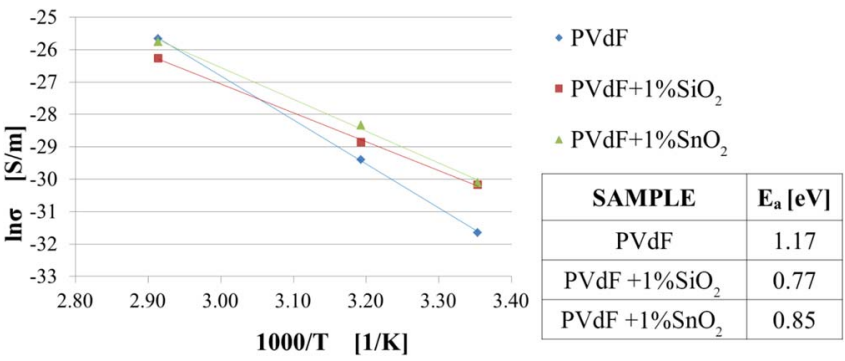

Figure 6. Arrhenius plot based on the temperature dependence of electronic conductivity of electrospun membranes and activation energy $\left(E_{a}\right)$ values. 

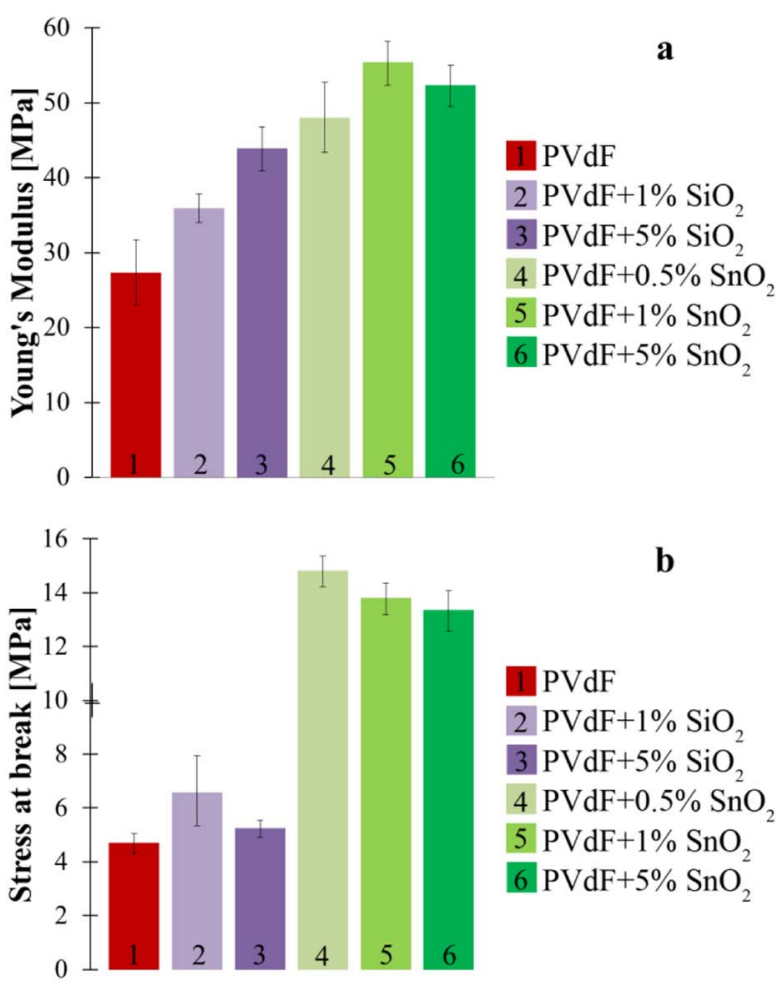

b
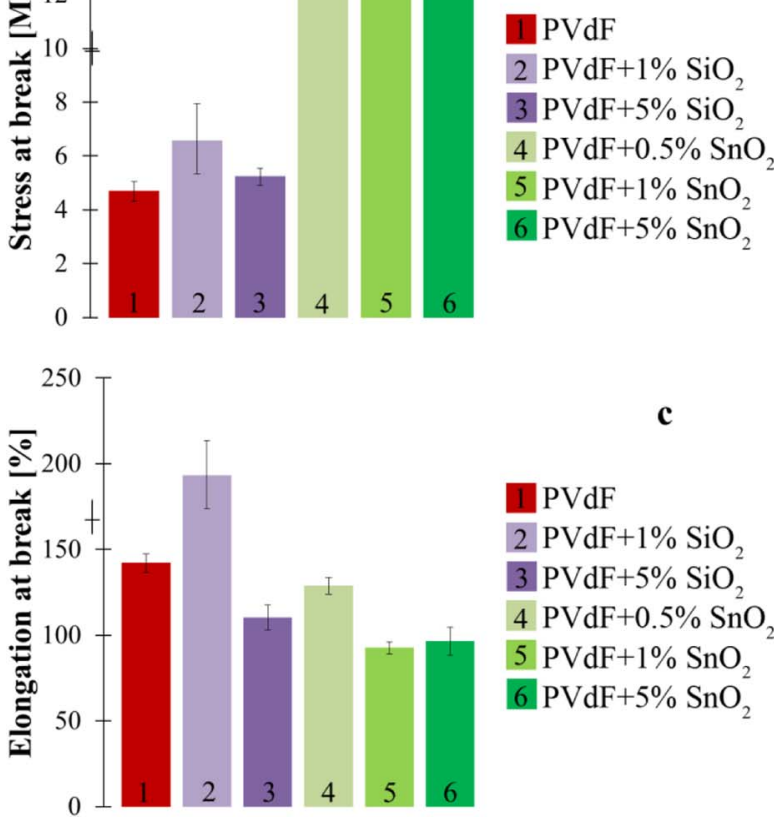

c

I PVdF

$2 \mathrm{PVdF}+1 \% \mathrm{SiO}_{2}$ $3 \mathrm{PVdF}+5 \% \mathrm{SiO}_{2}$ $4 \mathrm{PVdF}+0.5 \% \mathrm{SnO}_{2}$ $5 \mathrm{PVdF}+1 \% \mathrm{SnO}_{2}$ $6 \mathrm{PVdF}+5 \% \mathrm{SnO}_{2}$

Figure 7. Mechanical characterization of PVdF separators: elastic modulus (a), stress-at-break (b) and elongation-at-break (c).

tougher than the pristine PVdF. On the other hand, the addition of $\mathrm{SnO}_{2}$ greatly increased stress-at-break, with a consequent decrease in elongation-at-break, thus making the membrane stiffer than the pristine PVdF. Results show that a small amount of nanoadditive (about $1 \mathrm{wt} \%$ ) is highly effective in changing membrane mechanical properties, thus paving the way to the industrial use of this type of nanocomposite membranes. It is reported that, typical battery manufacturing procedures require separators able to sustain a stress of about $13 \mathrm{MPa}$ without being damaged. ${ }^{19}$ Among the investigated samples, $\mathrm{PVdF}$ loaded with $\mathrm{SnO}_{2}$ exhibits the best mechanical properties, suitable for this application. Therefore, the effect of $\mathrm{SnO}_{2}$ amount was further investigated in order to achieve the best performance in terms of mechanical property increase of the separator. In particular, it was possible to observe a remarkable increase of stress-at-break by adding only $0.5 \mathrm{wt} \%$ of $\mathrm{SnO}_{2}$ to PVdF, with respect to pristine polymer (Figure $7 \mathrm{~b}$ ). The elongation-at-break decreased with respect to pure $\mathrm{PVdF}$ but to a less extend than with higher concentrations (Figure 7c). To the best of our knowledge, the positive effect of $\mathrm{SnO}_{2}$ on mechanical and electric properties of $\mathrm{PVdF}$ lithium battery separators is here reported for the first time.

Finally, preliminary electrochemical tests were performed in LP30 on the electrospun membrane displaying the more suitable mechanical

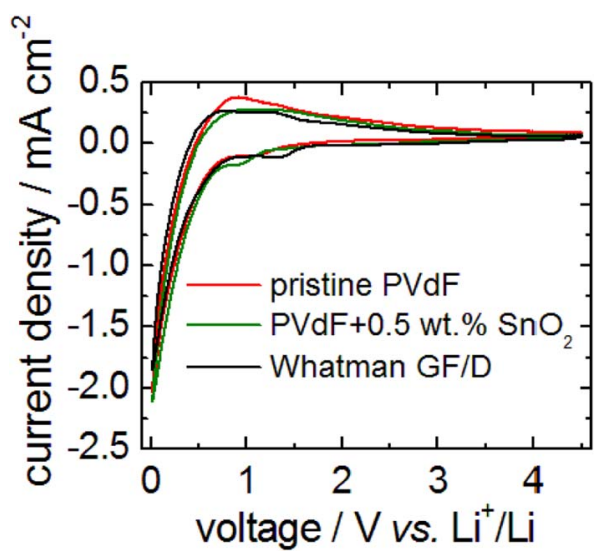

Figure 8. CVs at $1 \mathrm{mV} \mathrm{s}^{-1}$ in LP30 on glassy carbon electrodes between OCV (ca. $3.00 \mathrm{~V}$ vs. $\mathrm{Li}^{+} / \mathrm{Li}$ ) down to $0.02 \mathrm{~V}$ and, then, up to $4.50 \mathrm{~V}$ vs. $\mathrm{Li}^{+} / \mathrm{Li}$ with pristine $\mathrm{PVdF}$ (red line), $\mathrm{PVdF}+0.5 \mathrm{wt} \% \mathrm{SnO}_{2}$ (green line) and Whatman (black line) separators.

properties, i.e. $\mathrm{PVdF}$ containing $0.5 \mathrm{wt} \% \mathrm{SnO}_{2}$, and compared with those performed on pristine $\mathrm{PVdF}$ electrospun membrane.

Cyclic voltammetries (CVs) were performed in LP30 at $1 \mathrm{mV}$ $\mathrm{s}^{-1}$ in three-electrode configuration on glassy carbon $\left(0.636 \mathrm{~cm}^{2}\right)$ as working electrode and $\mathrm{Li}$ as reference and counter electrode, at $30^{\circ} \mathrm{C}$. The results are shown in Figure 8 and compared with those obtained with Whatman GF/D separator. The cells with the three separators perform almost identically. During the cathodic scan, it is first observed the reduction of the ethylene carbonate between 1.5 and $1.0 \mathrm{~V} \mathrm{vs} . \mathrm{Li}^{+} / \mathrm{Li}$, responsible of the formation of a surface passivation layer important in the case of a graphite anode, and the deposition of the lithium at lower potentials. Therefore, the cathodic currents are only related to the electrolyte and no evidence of the electroactivity of $\mathrm{PVdF}+0.5 \mathrm{wt} \% \mathrm{SnO}_{2}$ separator is recognizable.

$\mathrm{LiFePO}_{4}$ in half cells vs. Li with the two PVdF based separators were characterized by deep galvanostatic charge/discharge cycles. The voltage profile during the $1^{\text {st }}$ charge/discharge cycle at $\mathrm{C} / 10$ between 2.5 and $4.2 \mathrm{~V}$ with $\mathrm{PVdF}+0.5 \mathrm{wt} \% \mathrm{SnO}_{2}$ separator, shown in Figure $9 \mathrm{a}$, displays that the delivered capacity by $\mathrm{LiFePO}_{4}$ is very
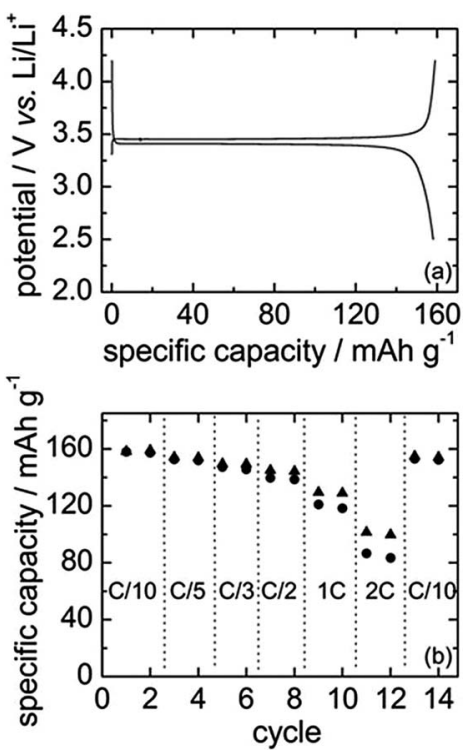

Figure 9. Charge/discharge voltage profile at $\mathrm{C} / 10$ of $\mathrm{LiFePO}_{4}$ electrode in half cell vs. $\mathrm{Li}$ with $\mathrm{PVdF}+0.5 \mathrm{wt} \% \mathrm{SnO}_{2}$ separator in $\mathrm{LP} 30$ (a); discharge capacities at different C-rates (2 cycles for each discharge rate) of $\mathrm{LiFePO}_{4}$ electrodes fully charged at $\mathrm{C} / 10$ with $\mathrm{PVdF}$ (triangle) and $\mathrm{PVdF}+0.5 \mathrm{wt} \%$ $\mathrm{SnO}_{2}$ separators (circle) in LP30 (b). 
close to the theoretical value of $170 \mathrm{mAh}^{-1}$. The discharge capacities at different $\mathrm{C}$-rates ( 2 cycles for each discharge rate) of $\mathrm{LiFePO}_{4}$ electrodes fully charged at $\mathrm{C} / 10$ in cells with $\mathrm{PVdF}$ (triangle) and with $\mathrm{PVdF}+0.5 \mathrm{wt} \% \mathrm{SnO}_{2}$ (circle) separators are shown in Figure $9 \mathrm{~b}$ and evince a good cycling performance for both cells. These preliminary results demonstrate that the use of the electrospun PVdF based separators may be a feasible option in lithium-ion cells.

\section{Conclusions}

In this work, PVdF electrospun separators loaded with inorganic nanoparticles of $\mathrm{SiO}_{2}$ and $\mathrm{SnO}_{2}$ were successfully produced by electrospinning. The presence of nanoparticles was confirmed by EDS and TGA analysis and did not affect solution electrospinnability and the final fiber morphology. We demonstrated that even a low amount of nanoparticles significantly affect membrane properties, in particular electrolyte uptake, mechanical properties and electrical conductivity. Indeed, fumed $\mathrm{SiO}_{2}$ enhances the rate of electrolyte uptake while $\mathrm{SnO}_{2}$ slightly decreases it with respect to pristine PVdF membrane, probably due to the high polarity of $\mathrm{SiO}_{2}$. As a matter of fact, all the investigated electrospun membranes display a remarkable higher electrolyte uptake than commercial Celgard separator. The addition of nanoparticles also affects $\mathrm{PVdF}$ mat mechanical properties. $\mathrm{SiO}_{2}$ tends to increase the toughness of the separator while $\mathrm{SnO}_{2}$ tends to increase its stiffness, thus improving PVdF mechanical properties and making it more suitable to resist to battery assembly procedures. Moreover, the addition of nanoparticles to electrospun PVdF decreases the activation energy for electronic conduction, thus improving the insulating properties of the membranes at high temperatures and providing a safer behavior in case of overheating. Preliminary tests on electrochemical cells with electrospun separators showed promising results for lithium-ion battery technology.

\section{Acknowledgments}

This research was done thanks to the financial support of Italian Ministry of Research and University (MIUR) and of the PLASMAT project (Alma Mater Studiorum - Università di Bologna FARB grant for fundamental research).

\section{References}

1. B. Scrosati and J. Garche, Journal of Power Sources, 195, 2419 (2010).

2. B. Scrosati, J Solid State Electrochem, 15, 1623 (2011).
3. J. Li, C. Daniel, and D. Wood, Journal of Power Sources, 196, 2452 (2011).

4. B. C. Melot and J. M. Tarascon, Accounts of Chemical Research, 46 (5), 1226 (2013).

5. C. Liu, F. Li, L.-P. Ma, and H.-M. Cheng, Adv. Mater, 22, E28 (2010).

6. M. Hu, X. Pang, and Z. Zhou, Journal of Power Sources, 237, 229 (2013).

7. P. Arora and Z. Zhang, Chem. Rev., 104, 4419 (2004).

8. X. Huang, J Solid State Electrochem, 15, 649 (2011).

9. S. S. Zhang, Journal of Power Sources, 164, 351 (2007)

10. T.-H. Cho, M. Tanaka, H. Onishi, Y. Kondo, T. Nakamura, H. Yamazaki, S. Tanase, and T. Sakai, Journal of Power Sources, 181, 155 (2008).

11. Y. M. Lee, J.-W. Kim, N.-S. Choi, J. A. Lee, W.-H. Seol, and J.-K. Park, Journal of Power Sources, 139, 235 (2005)

12. Y.-E. Miao, G.-N. Zhu, H. Hou, Y.-Y. Xia, and T. Liu, Journal of Power Sources, 226, 82 (2013).

13. F. Croce, M. L. Focarete, J. Hassoun, I. Meschini, and B. Scrosati, Energy Environ. Sci., 4, 921 (2011).

14. V. Aravindan, J. Sundaramurthy, P. S. Kumar, N. Shubha, W. C. Ling, S. Ramakrishna, and S. Madhavi, Nanoscale, 5, 10636 (2013).

15. Z. Zhong, Q. Cao, B. Jing, X. Wang, X. Li, and H. Deng, Materials Science and Engineering B, 177, 86 (2012).

16. Z. Dong, S. J. Kennedy, and Y. Wu, Journal of Power Sources, 196, 4886 (2011).

17. C. M. Costa, M. M. Silvab, and S. Lanceros-Mendez, RSC Adv., 3, 11404 (2013).

18. F. Liu, N. A. Hashim, Y. Liu, M. R. Moghareh Abed, and K. Li, Journal of Membrane Science, 375, 1 (2011).

19. X. Huang and J. Hitt, Journal of Membrane Science, 425-426, 163 (2013).

20. S.-S. Choi, Y. S. Lee, C. W. Joo, S. G. Lee, J. K. Park, and K.-S. Han, Electrochimica Acta, 50, 339 (2004).

21. Y. Liang, S. Cheng, J. Zhao, C. Zhang, S. Sun, N. Zhou, Y. Qiu, and X. Zhang, Journal of Power Sources, 240, 204 (2013).

22. P. Raghavan, X. Zhao, J.-K. Kim, J. Manuel, G. S. Chauhan, J.-H. Ahn, and C. Nah, Electrochimica Acta, 54, 228 (2008).

23. K.-U. Jeong, H. D. Chae, C. I. Lim, H. K. Lee, J.-H. Ahn, and C. Nah, Polym Int, 59, 249 (2010).

24. Y.-J. Kim, C. H. Ahn, M. B. Lee, and M.-S. Choi, Materials Chemistry and Physics, 127, 137 (2011).

25. M. Zaccaria, C. Gualandi, D. Fabiani, M. L. Focarete, and F. Croce, Journal of Nanomaterials, Vol. 2012, Article ID 216012 (2012).

26. H.-R. Jung, D.-H. Ju, W.-J. Lee, X. Zhang, and R. Kotek, Electrochimica Acta, 54, $3630(2009)$

27. M. Yanilmaz, Y. Lu, M. Dirican, K. Fu, and X. Zhang, Journal of Membrane Science, 456, 57 (2014).

28. M. Yanilmaz, C. Chen, and X. Zhang, Journal of Polymer Science, Part B: Polymer Physics, 51, 1719 (2013).

29. Y. Liang, L. Ji, B. Guo, Z. Lin, Y. Yao, Y. Li, M. Alcoutlabi,Y. Qiu, and X. Zhang, Journal of Power Sources, 196, 436 (2011).

30. J. Lee, C.-L. Lee, K. Park, and I.-D. Kim, Journal of Power Sources, 248, 1211 (2014).

31. J. Zhang, L. Yue, Q. Kong, Z. Liu, X. Zhou, C. Zhang, S. Pang, X. Wang, J. Yao, and G. Cui, Journal of The Electrochemical Society, 160(6), A769 (2013).

32. C. Arbizzani, F. Colò, F. De Giorgio, M. Guidotti, M. Mastragostino, F. Alloin, M. Bolloli, Y. Molméret, and J.-Y. Sanchez, Journal of Power Sources, 246, 299 (2014). 